
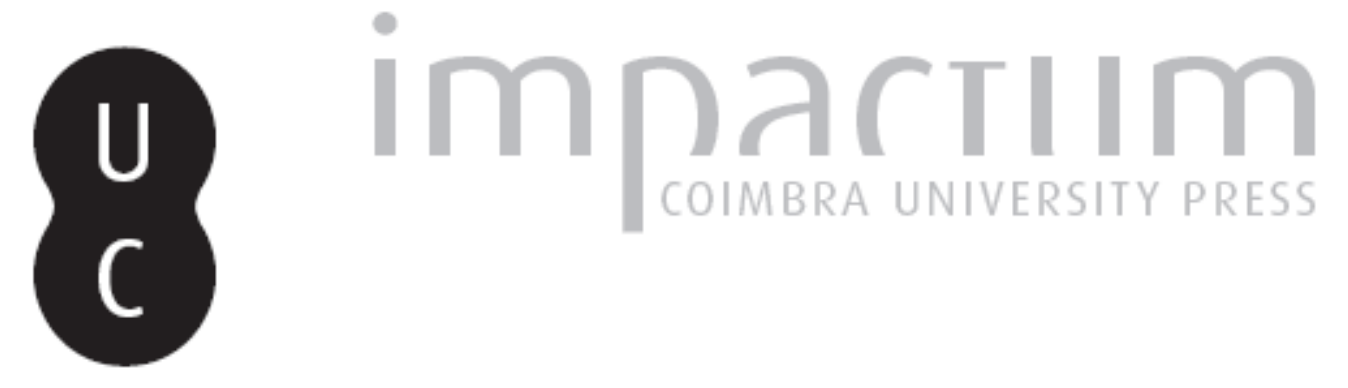

Nota sobre organización social y fuentes arqueológicas en el Norte hispano

Autor(es): $\quad$ González Rodríguez, M. ${ }^{a}$ Cruz

Publicado por: Faculdade de Letras da Universidade de Coimbra

URL persistente:

URI:http://hdl.handle.net/10316.2/37685

DOI:

DOI:http://dx.doi.org/10.14195/1647-8657_42_3

Accessed : $\quad$ 26-Apr-2023 10:40:50

A navegação consulta e descarregamento dos títulos inseridos nas Bibliotecas Digitais UC Digitalis, UC Pombalina e UC Impactum, pressupõem a aceitação plena e sem reservas dos Termos e Condições de Uso destas Bibliotecas Digitais, disponíveis em https://digitalis.uc.pt/pt-pt/termos.

Conforme exposto nos referidos Termos e Condições de Uso, o descarregamento de títulos de acesso restrito requer uma licença válida de autorização devendo o utilizador aceder ao(s) documento(s) a partir de um endereço de IP da instituição detentora da supramencionada licença.

Ao utilizador é apenas permitido o descarregamento para uso pessoal, pelo que o emprego do(s) título(s) descarregado(s) para outro fim, designadamente comercial, carece de autorização do respetivo autor ou editor da obra.

Na medida em que todas as obras da UC Digitalis se encontram protegidas pelo Código do Direito de Autor e Direitos Conexos e demais legislação aplicável, toda a cópia, parcial ou total, deste documento, nos casos em que é legalmente admitida, deverá conter ou fazer-se acompanhar por este aviso. 
CONIMBRIGA

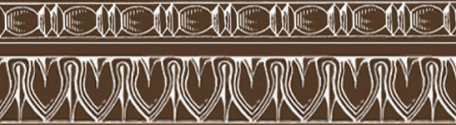

NSTITUTO DE ARQUEOLOGI

I

VOLUME XLII - 2003

A C U L D

UNIVERSIDADE DE COIMBR 
M.' CRUZ GonZÁlez RodRíGueZ

Catedrática de Historia Antigua

Universidad del País Vasco/Euskal Herriko Unibertsitatea

NOTA SOBRE ORGANIZACIÓN SOCIAL Y FUENTES ARQUEOLÓGICAS EN EL NORTE HISPANO

“Conimbriga" XLII (2003) p. 129-140

RESUMEN: Las características de las fuentes disponibles para el estudio y la comprensión de la organización social de los pueblos del norte hispano obligan a la interdisciplinariedad.

Desde esta perspectiva planteamos algunas reflexiones sobre la utilidad de los análisis arqueológicos y hacemos una llamada de atención sobre sus límites a la hora de ofrecer respuestas absolutas. En esta parcela, como en otras muchas de la Historia Antigua, siguen existiendo más problemas que soluciones.

RESUmo: As características das fontes disponíveis para o estudo e a compreensão da organização social dos povos do Norte hispano obrigam à interdisciplinaridade.

Sob esta perspectiva apresentamos algumas reflexões sobre a utilidade das análises arqueológicas e chamamos a atenção para as suas limitações quando se pretendem dar respostas absolutas. Neste domínio, como em muitos outros da História Antiga, continuam a existir mais problemas que soluções. 
(Página deixada propositadamente em branco) 


\title{
NOTA SOBRE ORGANIZACIÓN SOCIAL Y FUENTES ARQUEOLÓGICAS EN EL NORTE HISPANO
}

\author{
J. L. Maya
}

In memoriam

Parece hoy fuera de duda que el análisis exhaustivo de las fuentes escritas, y muy especialmente de las epigráficas, ha proporcionado en las últimas décadas avances muy significativos en la comprensión e interpretación de la organización social de los pueblos del norte peninsular (y en general de la llamada área indoeuropea) en época prerromana y romana (en SANTOS YANGUAS, 1995: 187-211 puede verse el estado de la cuestión). No obstante, a pesar de los progresos de la investigación sigue siendo muy difícil dar respuestas unívocas y ofrecer explicaciones históricas totalmente convincentes y exentas de problemas. Por ello resultan sumamente interesantes y estimulantes los acercamientos que en los últimos años, y partiendo, principalmente, de los logros producidos en el campo de la arqueología (AlARCÃo, 1999 (1); SASTRE PRATS, 2001 y 2002), aportan nuevos enfoques, proporcionan nuevas perspectivas e hipótesis para avanzar en la comprensión de estas sociedades pues, como acertadamente recuerda J. Alarcão, la reconstrucción histórica no puede limitarse sólo al estudio de las fuentes epigráficas. Éstas, como hace ya tiempo escribió el gran epigrafista L. Robert (1953: 12), no pueden estudiarse al margen del contexto del que forman parte lo que incluye el medio físico y el emplazamiento en el que aparece (ciudad, vicus, castellum, hallazgo aislado...).

Sólo desde la interdisciplinaridad, en la confluencia de los estudios provenientes del campo de la arqueología, la epigrafía y la linguística, teniendo en cuenta todos los datos disponibles (atendiendo a los nuevos hallazgos y los avances en el campo de la metodología 
y la Antropología) se podrá ir dibujando un discurso histórico coherente sobre un tema de estudio con serios problemas documentales que obligan a huir de posturas intransigentes.

No se debe olvidar una dificultad de partida, a saber, que nos encontramos en una zona marginal del imperio romano y ante un mundo eminentemente rural lo que condiciona el carácter de las fuentes disponibles. Por un lado se dispone de una producción epigráfica cuyo análisis no puede hacerse aisladamente sino que han de tenerse en cuenta siempre el mayor número o la totalidad de los documentos de la misma categoría. Por otro lado, en el estado actual de nuestros conocimientos (y al margen de las reutilizaciones, tal y como se puede comprobar en el caso de la epigrafía vadiniense dado que un buen número de estas inscripciones han sido halladas formando parte de construcciones recientes: RABANAL, García, 2001: N. ${ }^{\circ} 348$; 354; 364-365; 367; 371-375; 380 ; 382-384; 387; 400-401 y la posibilidad de traslados de inscripciones de un lugar a otro) contamos, con el problema de la falta de correspondencia entre las fuentes epigráficas y las arqueológicas dándose la paradoja de que existen ciertas zonas en las que las primeras sobre las unidades organizativas indígenas son ricas y abundantes, sin embargo, apenas tenemos información de la cultura material. Esto es algo que se observa de forma muy nítida en el caso de los astures orientales y de los cántabros occidentales - en concreto los vadinienses y los orgenomescos - sobre cuyo hábitat, a pesar de los trabajos del malogrado José Luis Maya (en último lugar MAYA, Cuesta, (eds.), 2001) y de Liz GuiRAL (1996) apenas sabemos nada (Cisneros, 1995; CASTANEdo, Cisneros, Díez, González y López, 1999). Al mismo tiempo, conviene recordar que una parte nada desdeñable del territorio ocupado por este grupo de población cántabro permanece hoy bajo las aguas del pantano de Riaño (pueblos de Riaño, La Puerta, Pedrosa del Rey y Anciles).

Esta situación es una traba para la interpretación histórica de forma que, por ejemplo, toda propuesta sobre el tipo de poblamiento y, en definitiva, del modelo social vadiniense queda, por el momento, y a pesar de los esfuerzos realizados en este sentido en los últimos años por nosotros mismos (GonZÁlez Rodríguez, 1997 y e.p.), I. Sastre y ahora J. Alarcão, en el terreno de las probabilidades cuyo posterior desarrollo permitirá comprobar su coherencia. Hasta que no tengamos prospecciones arqueológicas sistemáticas y resultados contrastables (y a sabiendas de que la arqueología tampoco va a responder a todos nuestros interro- 
gantes) tan sólo podemos plantear meras hipótesis más o menos convincentes a partir de la comparación con poblaciones de características similares pero, lamentablemente, aquí nos encontramos con el hecho incuestionable de que los datos proceden mayoritariamente de las fuentes epigráficas. De ahí que las reconstrucciones históricas propuestas sobre los vadinienses se centren exclusivamente en este tipo de fuentes. Son las únicas disponibles hasta el presente y, en consecuencia, es a partir del análisis de su contenido y de su reparto geográfico la única manera que tenemos de poder reconstruir algunas de las características de la organización social de este grupo de población cántabro. Las aquí propuestas por Alarcão nos parecen muy interesantes y sugerentes. Por nuestra parte, y por lo que conocemos para zonas muy similares de la actual Asturias en las que hasta no hace demasiado tiempo desarrollaban sus actividades ganaderas los conocidos "vaqueiros de alzada", no descartamos totalmente la posibilidad de que su tipo de poblamiento y economía nos puedan ofrecer algunos datos útiles para acercarnos a la comprensión de algunos aspectos de la forma de vida de este grupo de población. En cierta medida, los hemos tenido en cuenta al plantear nuestras hipótesis sobre la actividad ganadera trashumante que pretendía puntualizar la generalizada idea sobre su nomadismo. Sin embargo, somos plenamente consciente de que el desconocimiento de la arqueología de la zona no permite cerrar la puerta a otras propuestas.

Algo muy similar sucede, como hemos dicho, también en el caso de los astures centrales y orientales. En este caso los arqueólogos, dada la carencia de necrópolis y la pobreza de la documentación arqueológica, reconstruyen el territorio de las diferentes gentes de la Asturia transmontana a partir del reparto geográfico de las fuentes epigráficas con mención de unidades organizativas indígenas (MAYA, CUESTA (eds.), 2001: 257 y ss.).

Partiendo de estas premisas que tan sólo pretenden contextualizar los límites de la documentación nos parece sumamente atractivo y necesario que se interrogue a los datos arqueológicos para ver si éstos pueden rellenar los huecos que dejan sin cubrir las fuentes escritas. Esta nueva y podemos decir,"distante" mirada sirve para abrir nuevas puertas y (a sabiendas de que tampoco es una vacuna para todos nuestros males) tiene el innegable mérito de ayudar a completar la información de las fuentes escritas y, en algunos casos, permite puntualizar - y en 
ocasiones corregir - algunos de nuestros postulados. En definitiva, resulta sumamente saludable porque invita una vez más a reflexionar sobre problemas para los que seguimos sin tener una respuesta totalmente convincente.

Es precisamente desde esta incertidumbre - que la información arqueológica no logra disipar — desde la que planteamos algunos interrogantes. Éstos se siguen centrando (al igual que en anteriores trabajos: GONZÁlEZ RODRÍGUEZ, 1994 y 1998) en los problemas relativos al origen, la naturaleza, las equivalencias, las diferencias y las analogías entre las unidades organizativas indígenas expresadas en la epigrafía de época romana mediante genitivos de plural en el sistema onomástico de los habitantes de buena parte del área indoeuropa de Hispania y los términos latinos gens, gentilitas y cognatio.

Comenzando por la cuestión de su origen - a pesar de que nuestras palabras del año 1997 (pp. 75-76) puedan dar una impresión equívoca - pensamos que las unidades organizativas indígenas hunden sus raíces en la sociedad prerromana. Pero, lamentablemente e incluso las documentadas en inscripciones en lengua y alfabeto indígenas, las conocemos sólo en época romana. Además la gran mayoría, y los términos latinos utilizados son un claro exponente, se documentan en inscripciones latinas y en algunos casos muy tardías. Es lo que sucede precisamente en el caso de los cántabros y los astures, con lo que las evoluciones y las transformaciones no pueden dejarse de lado. Es decir, no estamos ante una realidad indígena inalterada sino que desde que finalizan las guerras de conquista (19 a. C.) hasta los ss. II-III en que se pueden fechar los testimonios epigráficos ha transcurrido un lapso de tiempo durante el cual la acción de Roma no pudo dejar incólume la sociedad conquistada. Esto por lo que respecta a los pueblos del norte, pero si nos referimos a otros grupos de población conquistados por Roma con anterioridad - como ocurre con los celtíberos — los riesgos son aún mayores. En otras palabras, la heterogeneidad del área indoeuropea (reflejada de forma clara en el trabajo de J. Alarcão) impide o, al menos, alerta sobre los peligros de cualquier tipo de generalización.

Por esta razón - y entrando en los aspectos relacionados con la naturaleza y las equivalencias entre unos y otras - compartimos las dudas expuestas ahora por Alarcão (y hace tiempo por Hoz, 1996) a cerca de la validez de la utilización del término cognatio (y añadimos cualquier de los otros dos) para designar a todas las unidades organiza- 
tivas expresadas por medio de los genitivos de plural en la epigrafía del área indoeuropea (cuestión que, al mismo tiempo, enlaza directamente con el espinosa tema de su contenido) dado que esta palabra latina sólo se ha documentado, hasta el presente, en dos inscripciones pertenecientes a astures (de carácter funerario y de finales del s. I) y vacceos (en una inscripción jurídica fechada en el año 134. Véanse las referencias y la bibliografía pertinentes en Alarcão). Como ya hemos apuntado en otro lugar (GoNZÁLEZ RoDRÍGUEZ, 1998: 325-347), resulta muy problemática proponer una equivalencia entre el contenido de los genitivos de plural documentos en la epigrafía celtibérica y latina de época republicana y el resto de estas menciones en la epigrafía latina más tardía. No tenemos datos que nos permitan afirmar que esas unidades eran cognationes idénticas a la cognatio de Montealegre del s. II. Además, la diferencia cronológica de unos y otros documentos junto con la diferencia cuantitativa entre los genitivos de plural documentados en las inscripciones celtibéricas y las escasísimas alusiones a unidades organizativas entre los vacceos obligan a la cautela. (En definitiva se plantea aquí la misma problemática y se hace la misma llamada de atención que en su día expusimos respecto a la generalización del término latino gentilitas para todas las unidades organizativas del área indoeuropea).

Y si esta comparación resulta problemática mucho más lo es la equiparación de los genitivos de plural de la epigrafía celtibérica republicana y la de los astures y cántabros vadinienses de los ss. II y III. La incertidumbre radica en que si ni tan siquiera tenemos la total seguridad - como ha señalado Hoz, 1996: 97-108, en especial 101, n. 14) de que los, aproximadamente, 80 genitivos de plural del tercer bronce de Botorrita aludan a un mismo tipo de unidad organizativa ¿cómo se va a poder afirmar la equivalencia entre éstos y las documentadas en textos epigráficos alejados, en ocasiones, por tres siglos?

Las mismas vacilaciones se repiten en la epigrafía norteña. Es lo que sucede en la comentada inscripción de Cofiño (Parres, Asturias) del año 268. Seguimos pensando, como en anteriores trabajos, que Onnacaum no tiene, necesariamente, que ser un grupo idéntico a la gens Pentiorum del mismo texto y nos inclinamos por su valoración como una cognatio, sin que ello quiera decir que tiene que ser totalmente idéntica a la cognatio Magilancum documentada un siglo antes.

Tardaremos en tener una respuesta totalmente segura pues no hay que olvidar la cronología tardía de esta inscripción y que el texto puede estar recogiendo formularios que ya han dejado de usarse en otras zonas 
— de forma muy clara entre los celtíberos - y, por tanto, cabe pensar que aunque se siga aludiendo a esas unidades, éstas a fines del s. III no tienen ya ni la misma operatividad ni el mismo papel que cuatro o dos siglos antes. En otras palabras, nuestra opinión, basada en la cronología de este texto (y no sólo en presupuestos nominalistas que por sí solos no sirven para nada), es que trátese de dos grupos idénticos (gentes) o diferentes (cognatio/gens) poco o nada tienen que ver ya, en unas fechas tan tardías, con las cognationes y gentes del alto imperio.

En conclusión, la generalización del término cognationes para designar la realidad que encubren los genitivos de plural del área indoeuropea sólo nos parece legítima en el caso de inscripciones de cronología semejante como es el caso de los genitivos de plural documentados entre los vadinienses a lo largo de los ss. II-III o el Magilanicum expresado en el sistema onomástico de un Mirobrigense - de Alcónetar (Garrovillas, Cáceres). Se trata de un nombre cómodo que en su acepción latina resulta ser el que mejor puede sintetizar las características que presentan las unidades que encubren los genitivos de plural. No obstante, somos conscientes de que esta no es una respuesta absoluta y la puerta de los interrogantes sigue abierta.

Por otro lado, y a pesar de las apariencias conviene subrayar que entre los cántabros vadinienses, y a diferencia de lo que sucede con los vacceos, son bastante abundantes estas menciones por lo que cualquier comparación debe de tener en cuenta esta diferencia ${ }^{1}$. En la actualidad, una vez hechas las correcciones oportunas y contabilizando los hallazgos más recientes tenemos, con seguridad, 5 menciones de genitivos en el norte de la Cordillera y 16 en el sur. Es decir, un total de 21 menciones de unidades organizativas indígenas ${ }^{2}$ expresadas mediante un genitivo de plural en el sistema onomástico.

1 Como acertadamente indica Alarcão, en nuestro trabajo del 97 - aludiendo al corpus del 86 - hay un error que hay que corregir, pues en p. 117, n. 358, la inscripción indicada con el número 178 no corresponde a los vadinienses. Igualmente se deben suprimir algunos de los genitivos de plural que habitualmente habíamos asignado a este grupo de población y que pueden ser interpretados, sencillamente, como antropónimos: se trata de $\operatorname{Arauu}(s)$ (en lugar de $\operatorname{Arau}(m)$; Taurino en dos ocasiones (en lugar de Taurino(rum) y Ubalacino (en vez de Ubalacino(rum). Ahora quizás se deben añadir a estas las recientes propuestas de Rabanal y García, op. cit., Arga(elus) en lugar de Arga(um) y Bodiues en lugar de Bodiues(cum).

2 Por otro lado, en nuestra publicación del 1997 (p. 119), cuando mencionamos 
Lo que sigue siendo imposible es - tanto en este caso como en cualquier otro - saber si tales menciones corresponden o no a familias de estatus social elevado. Así la afirmación de Alarcão de que entre los celtíberos el "comum da população se integrava em unidades organizativas" vendría comprobado por el tercer bronce de Botorrita donde parece ser que los individuos que portan los genitivos de plural son "de condición baja o no elevada" (Hoz, 1996: 101), pero, sin embargo, choca con los datos ofrecidos por, al menos, los dos primeros bronces de Botorrita ya que en el celtibérico los bintis y en el latino los magistratus, ambos personajes de la elite local, mencionan éstas en su sistema onomástico. En otras palabras, nos encontramos con el hecho de que ambas variables se constatan en un mismo grupo de población en epígrafes de cronología similar.

Por su parte en el caso cántabro se documenta también una situación peculiar y es que, como recuerda Alarcão, el princeps cantabrorum aparecido recientemente en una inscripción del s. I, no menciona el genitivo de plural (GoNZÁLEZ RoDRíGUEZ, 2002: 309-318), lo cual no permite vincular de forma mecánica las unidades organizativas indígenas con las elites indígenas (al menos a partir de esta temprana estela de territorio cántabro, la única que nos ha ofrecido, hasta el presente, información expresa de los miembros de la aristocracia local). Es difícil encontrar una respuesta única y satisfactoria para todas las variables (y la arqueología en este caso tampoco nos ayuda) y no creemos que fuese, simplemente, una cuestión de moda la que justifique la mención de las unidades organizativas indígenas.

Respecto a las gentes, y para evitar todo posible equívoco sobre nuestra consideración de que "las gentes son la base a partir de las cuales los romanos establecen los populi o ciuitates", queremos incidir una

la cantidad de 18 no nos estabamos refiriendo a las alusiones de genitivos de plural sino al número de inscripciones en las que se documentaban tales menciones sin alusión a la ciuitas (y en una misma inscripción puede recoger dos unidades organizativas indígenas: una referida al difunto y otra al dedicante). Esta es la razón por la que aparentemente (al margen del error de cita de nuestro catálogo) los datos ofrecidos por nosotros parecen no "cuadrar".

Para el resto de las cuestiones referidas a los vadinienses (amicitia, conuiuentes...) permitásenos remitir al lector a nuestras últimas reflexiones al respecto donde perfilamos y complementamos algunas de nuestras anteriores hipótesis: GonZÁLEZ RoDRÍGUEZ, M. C. (e. p.). 
vez más en que tal término es polisémico y que sirve para designar tanto al conjunto étnico de los astures y los cántabros (lo mismo puede verse en las fuentes literarias) como a una comunidad "política" indígena que posee sus propios "magistrados" y su "senado" (como sucede en el caso de los zoelas) y que encuentra su paralelo en las comunidades de los Alpes (gentes alpinae) documentadas en el 6 a. C. en el trofeo de la Turbia en Mónaco (Plinio, NH III, 136-138 (=CIL V 7817). Igualmente se utiliza también para designar una unidad organizativa inferior a la comunidad, populus/ciuitas. A este último grupo pertenecerían, pensamos, la gran mayoría de las gentes de las inscripciones de los ss. II-III de la Asturia transmontana - como sucede con la gens Cilurnigorum documentada en un epígrafe de fines del s. I - comienzos del s. II y hallado en el actual Gijón - que aludirían a una de las unidades integrantes del populus o ciuitas dentro de cuyos fines han sido halladas ${ }^{3}$. La situación sería la misma que la de la gens abilicorum respecto a la ciuitas de los orniacos en el año 152. Como es obvio - y esperamos que de nuestras palabras no se deduzca esa conclusión - la gens abilicorum no es equivalente a la ciuitas de la que forma parte (como tampoco lo son la gens zoelarum y la ciuitas zoelarum).

Por su parte, acerca de la expresión gentilitas conviene no olvidar que se trata también de un término polisémico del que tenemos sólo dos testimonios epigráficos en la Hispania indoeuropea y no sabemos si ambos tienen contenido idéntico ${ }^{4}$. Por la misma razón no podemos saber si tras algunos genitivos de plural se pueden esconder unidades organizativas similares a las gentilitates de los zoelas. En cualquier caso pensamos que la respuesta sólo nos resulta afirmativa en el caso de los astures pero tampoco en esta ocasión existe una contestación única e

3 Para Maya y Cuesta (eds.), 2001: 257 las gentes de la Asturia transmontana ejercerían su control sobre un territorio relativamente limitado. En unos casos éste correspondería a un castro y en otros, como en el caso de los cilurnigos, a dos o más. El radio de acción de esta última gens se calcula entre 10/15 km.

4 Rodríguez, P., 1994: 67-71. Sobre la gentilitas Gapeticorum de Cáceres vid. ahora la propuesta de J. C. Búa, Estudio de la teonimia lusitano-gallega. Tesis Doctoral. Universidad de Salamanca 2000 (original dactilografiado), 505 que propone la lectura: Cap(erensium) et [e]orum Gen(io) [c]i[u]itatis. (citado en J. M. Vallejo, Estudio de la antroponimia indígena de la Lusitania romana, Vitoria-Gasteiz 2002, Tesis Doctoral. Original dactilografiado: 142). Si esta interpretación es correcta debemos suprimir este texto a la hora de aludir a las gentilitates quedando este término reducido, por el momento, al ámbito astur. 
irrefutable. Así, en el caso de los arronidaeci et coliacini de los astures transmontanos podemos estar ante gentilitates - tal y como propone Alarcão - pero ¿no podría tratarse también de gentes, dada la cronología del epígrafe y la abundante presencia de las menciones de gentes en esta zona del territorio astur?

Pero si bien para esta cuestión la documentación arqueológica tampoco nos puede ofrecer una respuesta categórica; lo que esta fuente permite, tal y como expone AlARCÃo, es una aproximación a la naturaleza y la amplitud de las gentilitates de los zoelas y la hipótesis resultante parece coherente con lo que las fuentes epigráficas permitían deducir (vid. GonZÁlEZ RodRíGUEZ, 1997: 81-82) ${ }^{5}$. En consecuencia, se puede decir que en este caso la contrastación de ambas documentaciones coincide en gran medida.

En definitiva, las fuentes arqueológicas pueden arrojar luz sobre ciertos aspectos (lamentablemente, no de detalle) para los que la documentación escrita no ofrece información y al revés y, en ocasiones, las respuestas de ambos registros pueden ir en la misma dirección con lo que, como señalábamos al principio, es necesaria la complementariedad pues ninguno de los dos tiene la verdad absoluta. El único camino sigue siendo la investigación contrastada que permita corregir los posibles excesos e intentar encontrar respuestas históricamente rigurosas y convincentes, siendo conscientes de que también en este caso como sucede con otros temas de la Historia de Grecia y Roma hay aspectos "que probablemente no llegaremos a conocer jamás" (FINLEY, 1986, 2).

\section{REFERENCIAS BIBLIOGRÁFICAS}

(se citan sólo las que no aparecen recogidas por Alarcão)

Castanedo, T., Cisneros, M., Díez, A., GonzÁlez, M. R. y LóPez P., 1999: "Los valles occidentales de Cantabria: el poblamiento de Montaña durante la II Edad del Hierro y época romana", en Regio Cantabrorum, Santander: 143-148.

Cisneros, M., 1995: "La arqueología de los cántabros: una reflexión metodológica", Zephyrus, XLVIII: 223-234.

5 Por su parte en ) Agubri, creemos que aquí el signo ) se refiere a castellum, tal y como permite deducir el sufijo -bri frecuente en nombres de lugar: véase Hoz, 1994: 349-361. 
Finley, M., 1986: Historia Antigua. Problemas Metodológicos, Barcelona (1ª edic. en castellano).

GonZÁlez RodRíGUEZ, M. C., 2002: “Anotaciones sobre las elites indígenas cántabras y su integración por parte de Roma", en Homenaje a P. Gainzarain (= Anejos de Veleia. Series Minor 17), Vitoria: 309-318.

GonZÁLEZ RodríGuez, M. C., (e. p.), "Epigrafía y sociedad: el ejemplo vadiniense”, en Actas del II Encuentro de Historia de Cantabria, (Santander, Noviembre 2003).

Hoz, J. DE, 1994: "Castellum Auiliobris. Los celtas del extremo occidental continental", en BIELMEIER, R. y STEMPEL, R. (eds.), Indogermanica et caucasica: Fesrschrift für K. H. Schmidt zum 65. Geburtstag, Berlín: 349-361.

Hoz, J. DE, 1996: "Consideraciones adicionales sobre la estructura del texto", en BELTRÁN, F. (ed.), El tercer bronce de Botorrita (Contrebia Belaisca), Zaragoza: 97-108 .

Liz Guiral, J. 1996, "Epigrafía y arqueología vadinienses", en Actas ArqueoLeón. Historia de León a través de la Arqueología, León: 83-90.

Maya, J. L., F. Cuesta, F. (eds.), 2001, El Castro de La Campa Torres. Período Prerromano (Serie Patrimonio 6), Gijón.

RoBert, L., 1953: "Communication inaugurale”, en Actes du Deuxième Congrès International d'Épigraphie Grecque et Latine, París: 1-20. 